\title{
CFD SIMULATION TO THE FLOW FIELD OF VENTURI INJECTOR
}

\author{
Xingfa Huang *, Guangyong Li, Miao Wang \\ College of Water Conservancy and Civil Engineering, China Agricultural University, Beijing \\ 100083, China \\ * Corresponding author, Address: P. O. Box 104, China Agricultural University, 17 Qinghua \\ donglu, Beijing,100083,P.R. China, Tel:+86-10-62737874, Fax:+86-10-62736273, Email: \\ huangxingfa@cau.edu.cn
}

Abstract: Venturi injector is widely used in fertigation system due to its obvious advantages such as cheap and robust system without mobile pieces, simple structure, convenient to operation, stable performance, needless of external energy for operation etc. At present, the hydraulic parameters such as suction capacity (injection rate) for the most of the Venturi injectors produced domestically are not very desirable. In this paper, CFD (Computational Fluid Dynamics) method was used to simulate the inner flow field of the Venturi injectors, and the relationships among the structure parameters (i.e., throat length $\mathrm{L}$, throat diameter $\mathrm{D}$, slot diameter $\mathrm{Da}$ ) and suction capacity $\mathrm{q}$, and the optimal structure sizes of the Venturi injector were analyzed. The results show that when the inlet pressure and the slot position are kept unchanged as the sample one, the suction capacity of Venturi injector increases with the decrease of throat diameter $\mathrm{D}$ and throat length $\mathrm{L}$, and the increase of slot diameter Da; while keeping the slot diameter Da, throat diameter $\mathrm{D}$ and throat length L unchanged, the suction capacity of Venturi injector q increases with the increase of inlet pressure P. The optimal combination of the structural parameters in this size was selected as follows: throat diameter $\mathrm{D}=8 \mathrm{~mm}$, slot diameter $\mathrm{Da}=18.5 \mathrm{~mm}$, and throat length $\mathrm{L}=14 \mathrm{~mm}$. In this case, the suction capacity of the Venturi injector $\mathrm{q}=1.203 \mathrm{~m} 3 / \mathrm{h}$. The results can provide theoretic support for domestic Venturi injector research, design and manufacturing.

Key words: venturi injector, suction capacity (injection rate), inlet pressure, structure parameters, numerical simulation

Please use the following format when citing this chapter:

Huang, X., Li, G. and Wang, M., 2009, in IFIP International Federation for Information Processing, Volume 294, Computer and Computing Technologies in Agriculture II, Volume 2, eds. D. Li, Z. Chunjiang, (Boston: Springer), pp. 805-815. 


\section{INTRODUCTION}

The application of chemical products in pressurized irrigation systems presents evident advantages. This technique, called chemigation, is widely used in sprinkler irrigation and drip irrigation systems (Johnson et al, 1986). The fertirrigation system needs an injector. Venturi injector is the one that widely used in the chemigation system in small and medium size farms (Manzano Juárez J. et al, 2005). The pressure drop through a venturi must be sufficient to create a negative pressure (vacuum) as measured relative to atmospheric pressure. Under these conditions the fluid from the tank will flow into the injector.

As the rapid development of agricultural modernization in China, it is of importance for sprinkler and micro irrigation system to apply in the field crops, facility agriculture, industrialized agriculture and landscape etc (Zhao Jingcheng et al, 1999). Fertigation in drip irrigation system is the optimal selection for fertilizing perennial crops in root zone, which is also the important measure to obtain high yields, good quality and efficient use of water and fertilizer. According to the investigation of Irrigation Training and Research Center, Science \& Engineering College of California, U.S.A., in normal case with fertigation in drip system, $25 \%$ fertilizer can be saved, and more labors and energies be saved (Li jiusheng et al, 2003; 2004). At present, the common fertilizing equipments in China include self-pressured injecting device, pressure difference injecting device, fertigation pump, fertilizer container, Venturi injector, jet fertigation device etc.(Shen Xuemin, 2000).

Venturi injector is widely used in fertigation system due to its obvious advantages such as cheap system, simple structure, robust system without mobile pieces, convenient to operation, labor saving, stable performance, needless of external energy for operation etc. (Manzano Juárez J. et al, 2005; Shen Xuemin, 2001; Sha Yi et al, 1995). Venturi injector is one of the basic types of injector in subsurface drip irrigation system (Graham Harris, 2005)

Some researches on performance of Venturi injector in irrigation system were carried out. Better fertilizer distribution in the greenhouse experiment was obtained with Venturi one (Bracy R P et al, 2003). The effect of chemical temperature change on the injection flow rate of a Venturi injector was evaluated by Yuan Z et al (2000). Manzano Juárez J et al (2005) carried out the study on hydraulic modeling of Venturi injector using CFD, with its predictions for the total pressuer losses had a small error, less than $2 \%$.

The study of Venturi injector in irrigation system in China began at late 1970's, when advanced Western micro irrigation system came to China. There were not series products then and up to now, and mostly relied on importing from foreign companies. As the rapid development of drip irrigation and fertigation technologies, reliable performance of Venturi injector was required. This requirement leads to the further research on Venturi injector. But at present, most studies mainly focus on theoretic 
analyses and experimental research on its hydraulic performances such as discharge, suction capacity (injection rate), pressure at throat, outlet water velocity etc., which needs a huge amount of experiments (Sha Yi et al, 1995; Shen Xuemin, 2001; Li Baijun et al, 2001). As the development of computer and simulation technologies, numerical simulation can do the similar things with its great advantages such as high efficiency, low cost, wide suitability to various variables etc.. It is widely extended and used in different areas (Chen Zuobing et al, 2005). In this article, The CFD (Computational Fluid Dynamics) numerical calculation method was used to simulate the performance of Venturi injector.

\section{DESIGN AND METHODS}

\subsection{Structure and parameters of Venturi Injector}

A sample of Venturi injector was designed and made before numerical simulation, as shown at Figure 1. For this sample Venturi injector, its inlet diameter is $d_{1}=30 \mathrm{~mm}$, diameter of suction pipe is $d_{2}=18 \mathrm{~mm}$, the slope of inlet and out let of throat is $17.5^{\circ}, 4^{\circ}$, respectively. The throat diameter is $D=12 \mathrm{~mm}$, and its length is $L=27 \mathrm{~mm}$; The slot is at the top of suction pipe, and its diameter is $D_{\mathrm{a}}=17 \mathrm{~mm}$. After the sample was made, its performance test was carried out. The experiment condition was set as follows: inlet pressure was $P=0.21 \mathrm{MPa}$, outlet pressure was 0 . Then the measured inlet discharge was $Q_{1}=6.27 \mathrm{~m}^{3} / \mathrm{h}$, outlet discharge was $Q_{2}=6.95 \mathrm{~m}^{3} / \mathrm{h}$, while the suction capacity was $q=0.68 \mathrm{~m}^{3} / \mathrm{h}$.

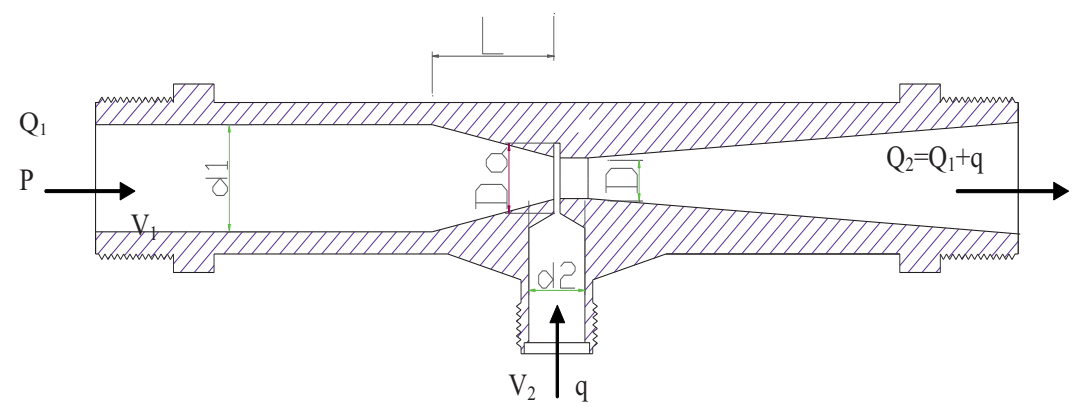

Fig. 1 Schematic diagram of Venturi injector

( $L$ is the throat length; $D$ is the throat diameter; $D_{\mathrm{a}}$ is the slot diameter; $d_{1}, d_{2}$ are the inlet diameter and suction pipe diameter, respectively; $P$ is the inlet water pressure; $Q_{1}$, $Q_{2}, q$ are the discharges from inlet, outlet, suction part; $v_{1}, v_{2}$ are the flow rates at inlet and suction part, respectively) 


\subsection{CFD Models of Venturi Injector and Its Validation}

\subsubsection{CFD Models}

In this case, one of the CFD software, FLUENT 6.1.22 was used to simulate the performance of Venturi injector. It applies Definite Volume Method to transfer the differential equation to algebraical equation, and the approach of First Order Windward was used. For the solution of pressure velocity coupled dispersed equations, typical SIMPLE algorithm was used (Chen Zuobing et al, 2005), in which the convergent value that is the difference between two variable values of conjoint alternation was less than $10^{-4}$. The three dimensional geometric model of the Venturi injector sample was established by using the software of GAMBIT 2.04, in which hexahedron grid with its size of $1 \mathrm{~mm}$ was used to divide its grids for most parts, except for the slot part, which non structure grid with its size of $1 \mathrm{~mm}$ was used. The total number of grids was 162138 .

The inlet flow rate of the sample Venturi injector was: $v_{1}=4 Q_{1} /\left(\pi d_{1}^{2}\right)=4 *$ $(6.27 / 3600) /\left(\pi^{*} 0.03^{2}\right)=2.46 \mathrm{~m} / \mathrm{s}$; suction flow rate was : $v_{2}=4 q /\left(\pi d_{2}{ }^{2}\right)=4 *(0.68 / 3600) /\left(\pi^{*} 0.018^{2}\right)=0.742 \mathrm{~m} / \mathrm{s}$. From above data, and taking $\gamma=0.0101 \mathrm{~cm}^{2} / \mathrm{s}$, Renault values of inlet and suction part of the injector can be calculated, and they are $R e_{1}=v_{1} d_{1} / \gamma=(2.46 * 100) *(30 / 10) / 0.0101=$ $73069>2000, R e_{2}=v_{2} d_{2} / \gamma=(0.742 * 100) *(18 / 10) / 0.0101=13224>2000$, respectively. Thus, the water flow status of these two parts was considered as turbulence. So the flow status of the sample injector was regarded as unconstringent turbulent flow, and the $\kappa-\varepsilon$ turbulent flow model was used then (Li Baijun et al, 2001). By calculating the turbulent flow intensity, $I=0.16 R e^{-0.125}$, the turbulent flow intensity of inlet and suction part of the injector was $I_{1}=3.9 \%$ and $I_{2}=4.8 \%$, respectively.

Besides the Continuity Equation (i.e., Mass Conservation Equation) and Navier-Stokes Equation (i.e., Monmentum Conservation Equation), turbulent flow equation was also needed as one of the basic control equations. In the Descartes Coordinate system, the forms of the basic control equations were list as follows (Wang Fujun, 2004; Li Yongxin, et al, 2004):

Continuity Equation

$$
\frac{\partial u}{\partial x}+\frac{\partial v}{\partial y}+\frac{\partial w}{\partial z}=0
$$


Navier-Stokes Equation

$$
\begin{gathered}
\frac{\partial(\rho u)}{\partial t}+\nabla \cdot(\rho u \mathrm{u})=-\frac{\partial p}{\partial x}+\mu \nabla^{2} u+F_{x} \\
\frac{\partial(\rho v)}{\partial t}+\nabla \cdot(\rho v \mathrm{u})=-\frac{\partial p}{\partial y}+\mu \nabla^{2} v+F_{y} \\
\frac{\partial(\rho w)}{\partial t}+\nabla \cdot(\rho w \mathrm{u})=-\frac{\partial p}{\partial z}+\mu \nabla^{2} w+F_{z}
\end{gathered}
$$

Where, $t$ is time; $\boldsymbol{u}$ is flow rate vector, and $u, v, w$ are the tree sub values of $\boldsymbol{u}$ in directions of $x, y, z ; \rho$ and $\mu$ are the water density and dynamical viscosity coefficient, respectively; $P$ is the water pressure on the micro flow unit; $F_{x}, F_{y}, F_{z}$ are the mass forces of the micro flow unit in the directions of $x, y, z$. If the mass force was just gravity, and the direction of $z$ was vertical upward, in this case, we can get that $F_{x}=0, F_{y}=0, F_{z}=-\rho g$.

In standard $k-\varepsilon$ turbulent flow model, the expression of turbulent flow kinetic energy $k$ and dissipation ratioe was listed as follows (Wang Fujun, 2004; Li Yongxin et al, 2004):

$$
\left.k=\frac{1}{2} \overline{\left(u^{\prime 2}\right.}+\overline{v^{\prime 2}}+\overline{w^{\prime 2}}\right) \quad \varepsilon=\frac{\mu}{\rho} \overline{\left(\frac{\partial u_{i}^{\prime}}{\partial x_{k}}\right)\left(\frac{\partial u_{i}^{\prime}}{\partial x_{k}}\right)}
$$

Where, $u^{\prime}, v^{\prime}, w^{\prime}$ are the fluctuation values of flow rate in the three directions of $x, y, z$.

In the standard $k-\varepsilon$ model, $k$ and $\varepsilon$ are two unkown variables. The corresponding control equation is (Chen Zuobing et al, 2005):

$$
\begin{aligned}
& \frac{\partial}{\partial t}(\rho k)+\frac{\partial}{\partial x_{i}}\left(\rho k u_{i}\right)=\frac{\partial}{\partial x_{j}}\left[\left(\mu+\frac{\mu_{t}}{\sigma_{k}}\right) \frac{\partial k}{\partial x_{j}}\right]+G_{k}-\rho \varepsilon \\
& \frac{\partial}{\partial t}(\rho \varepsilon)+\frac{\partial}{\partial x_{i}}\left(\rho \varepsilon u_{i}\right)=\frac{\partial}{\partial x_{j}}\left[\left(\mu+\frac{\mu_{t}}{\sigma_{\varepsilon}}\right) \frac{\partial \varepsilon}{\partial x_{j}}\right]+\frac{C_{1 \varepsilon} \varepsilon}{k} G_{k}-C_{2 \varepsilon} \rho \frac{\varepsilon^{2}}{k}
\end{aligned}
$$

Where, $\mu_{t}$ is turbulent viscosity efficient; $G_{k}$ is the turbulent kinetic energy $k$ produced by average velocity gradient; $\sigma_{k}, \sigma_{\varepsilon}, C_{1 \varepsilon}, C_{2 \varepsilon}$ are constants. The meaning of other variables are the same as previous mentioned. The detailed expression of the equation can be seen in literature of Wang Fujun (2004).

By numerical simulation to the flow field of the sample Venturi injector, its performance such as suction capacity can be obtained.

\subsubsection{Validation of the CFD Models}

The simulation was carried out according to the above model, the structure size of the sample Venturi injector as at Figure 1, and its running parameters. The simulated suction capacity was $0.720 \mathrm{~m}^{3} / \mathrm{h}$, while the actual measured suction capacity was $q=0.68 \mathrm{~m}^{3} / \mathrm{h}$. The error between these 
two values was $5.88 \%$, which showed that the model and its solution approach are reasonable. This model can be applied to simulation analyses of practical Venturi injector performance.

\section{RESULTS AND DISCUSSION}

\subsection{Effects of Key Parameters of Venturi Injector on Suction Capacity}

\subsubsection{Effects of throat diameter and slot diameter on suction capacity}

In this case, throat diameter and slot diameter were changed, while other structural parameters and inlet pressure kept unchanged. The simulation results are showed at Figure 2, which show that the correlation between the suction capacity and slot diameter under different throat diameters are quite well. When fixed slot diameter $D_{\mathrm{a}}$, the suction capacity of the sample injector decreases as the throat diameter $D$ is increased; While fixed throat diameter $D$, the suction capacity of the sample injector increases as the slot diameter $D_{\mathrm{a}}$ is increased. The effect of throat diameter $D$ on suction capacity is much more sensitive than that of slot diameter $D$ on it.

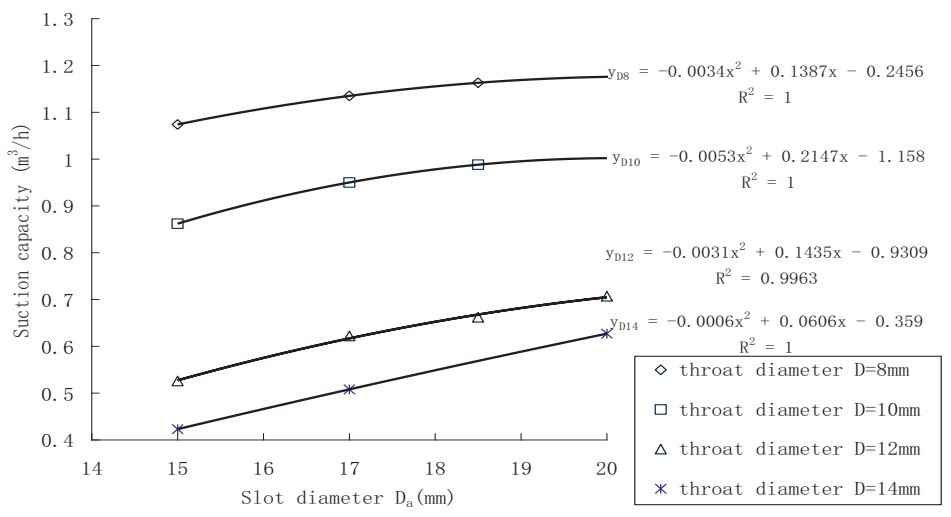

Fig. 2 Suction capacity changing curves under different slot diameters 


\subsubsection{Effects of throat length and slot diameter on suction capacity}

In this case, throat length and slot diameter were changed, while other structural parameters and inlet pressure kept unchanged. The simulation results are showed at Table 2 and Figure 3.

The results from Figure 3 show that when fixed slot diameter $D_{\mathrm{a}}$, the suction capacity of the sample injector decreases as the throat length $\mathrm{L}$ is increased; While fixed throat length $\mathrm{L}$, the suction capacity of the sample injector increases as the slot diameter $D_{\mathrm{a}}$ is increased. The effect of slot diameter $D_{\mathrm{a}}$ on suction capacity is much more sensitive than that of throat length $L$ on it.

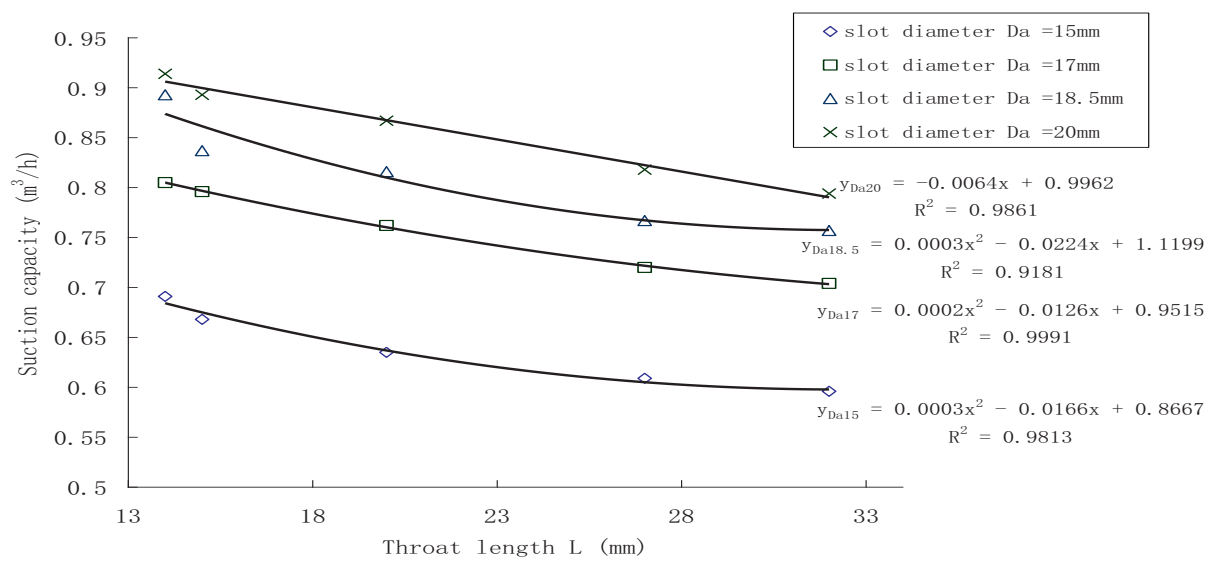

Fig. 3 Suction capacity changing curves under different slot diameters and throat length

\subsubsection{Effects of throat diameter and throat length on suction capacity}

In this case, throat length $\mathrm{L}$ and throat diameter $D$ were changed, while other structural parameters and inlet pressure kept unchanged. The simulation results are showed at Figure 4. 


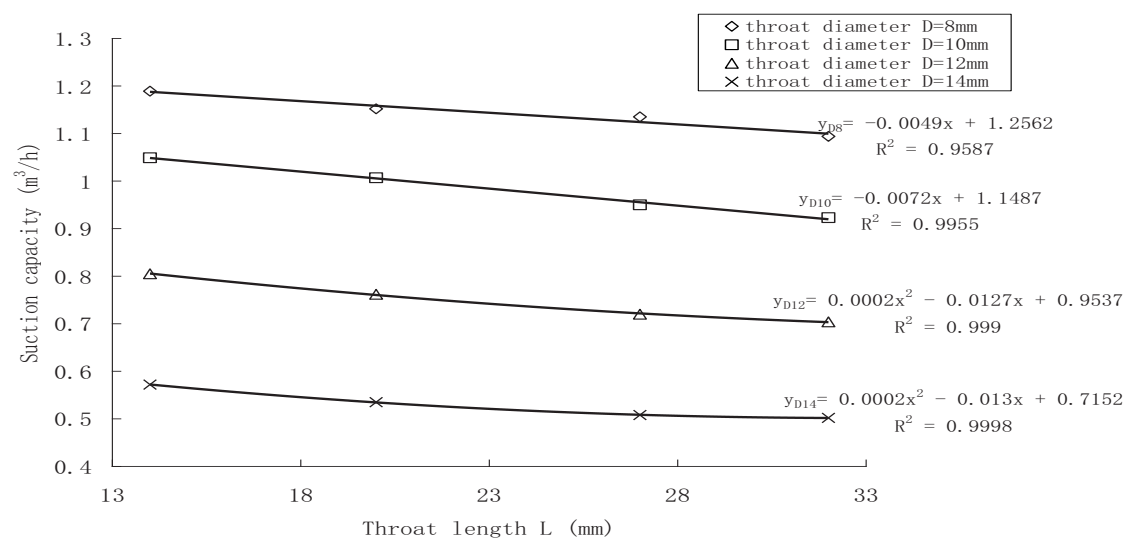

Fig. 4 Suction capacity changing curve under different throat diameters and throat lengths

The results from Figure 4 show that when fixed the throat length $L$, the suction capacity of the sample injector decreases as throat diameter $D$ is increased; While fixed throat diameter $D$, the suction capacity of the sample injector also decreases as the throat length $L$ is increased, and their correlation was better. The effect of throat diameter $D$ on suction capacity is much more sensitive than that of throat length $L$ on it.

\subsubsection{Effects of inlet pressure on suction capacity}

In this case, inlet pressure was changed, while the structural parameters of sample injector kept unchanged. The simulation results are showed at Figure 5 , which show that the suction capacity of Venturi injector increases as its inlet pressure $P$ increases.

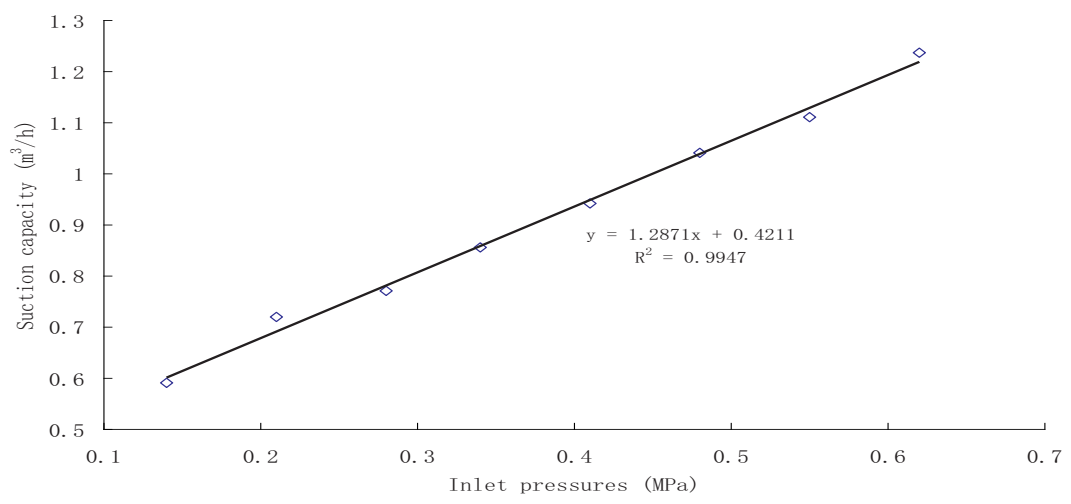

Fig. 5 Suction capacity under different inlet pressures

As mentioned above, the main sensitive factors to affect suction capacity of Venturi injector are throat diameter $D$, slot diameter $D_{\text {a }}$, and throat length $L$. The order of its sensitivity from strong to weak is as follows: first throat diameter $D$, then slot diameter $D_{\text {a }}$, and last throat length $L$. 


\subsection{Full Factors Experiment for Suction Capacity of Venturi Injector with Main Structural Parameters}

In order to analyze the regulation of the effects of different factors on suction capacity of Venturi injector, Full Factors Simulation Experiment were carried out based on previous simulation. In this experiment period, slot diameter $D_{\mathrm{a}}$ was selected as $15 \mathrm{~mm}, 17 \mathrm{~mm}$ and $18.5 \mathrm{~mm}$; throat diameter $D$ was selected as $8 \mathrm{~mm}, 10 \mathrm{~mm}$ and $12 \mathrm{~mm}$; while throat length $L$ was selected as $14 \mathrm{~mm}, 20 \mathrm{~mm}$ and $27 \mathrm{~mm}$. The layout of experiment and the results were shown as Table 1.

Table 1 Experimental results with all 3 factors by 3 levels

\begin{tabular}{|c|c|c|c|}
\hline Treatments & $\mathrm{Q}_{1}\left(\mathrm{~m}^{3} / \mathrm{h}\right)$ & $\mathrm{q}\left(\mathrm{m}^{3} / \mathrm{h}\right)$ & $\mathrm{Q}_{2}\left(\mathrm{~m}^{3} / \mathrm{h}\right)$ \\
\hline$D_{\mathrm{a}}=15, D=8, L=14$ & 5.709 & 1.137 & 6.846 \\
\hline$D_{\mathrm{a}}=15, D=8, L=20$ & 5.709 & 1.097 & 6.806 \\
\hline$D_{\mathrm{a}}=15, D=8, L=27$ & 5.709 & 1.073 & 6.782 \\
\hline$D_{\mathrm{a}}=15, D=10, L=14$ & 5.831 & 0.951 & 6.782 \\
\hline$D_{\mathrm{a}}=15, D=10, L=20$ & 5.831 & 0.908 & 6.739 \\
\hline$D_{\mathrm{a}}=15, D=10, L=27$ & 5.831 & 0.862 & 6.693 \\
\hline$D_{\mathrm{a}}=15, D=12, L=14$ & 5.902 & 0.691 & 6.593 \\
\hline$D_{\mathrm{a}}=15, D=12, L=20$ & 5.902 & 0.635 & 6.537 \\
\hline$D_{\mathrm{a}}=15, D=12, L=27$ & 5.902 & 0.609 & 6.511 \\
\hline$D_{\mathrm{a}}=17, D=8, L=14$ & 5.709 & 1.189 & 6.898 \\
\hline$D_{\mathrm{a}}=17, D=8, L=20$ & 5.709 & 1.152 & 6.861 \\
\hline$D_{\mathrm{a}}=17, D=8, L=27$ & 5.709 & 1.135 & 6.844 \\
\hline$D_{\mathrm{a}}=17, D=10, L=14$ & 5.831 & 1.049 & 6.880 \\
\hline$D_{\mathrm{a}}=17, D=10, L=20$ & 5.831 & 1.007 & 6.838 \\
\hline$D_{\mathrm{a}}=17, D=10, L=27$ & 5.831 & 0.950 & 6.781 \\
\hline$D_{\mathrm{a}}=17, D=12, L=14$ & 5.902 & 0.805 & 6.707 \\
\hline$D_{\mathrm{a}}=17, D=12, L=20$ & 5.902 & 0.762 & 6.664 \\
\hline$D_{\mathrm{a}}=17, D=12, L=27$ & 5.902 & 0.720 & 6.622 \\
\hline$D_{\mathrm{a}}=18.5, D=8, L=14$ & 5.709 & 1.203 & 6.912 \\
\hline$D_{\mathrm{a}}=18.5, D=8, L=20$ & 5.709 & 1.178 & 6.887 \\
\hline$D_{\mathrm{a}}=18.5, D=8, L=27$ & 5.709 & 1.163 & 6.872 \\
\hline$D_{\mathrm{a}}=18.5, D=10, L=14$ & 5.831 & 1.076 & 6.907 \\
\hline$D_{\mathrm{a}}=18.5, D=10, L=20$ & 5.831 & 1.036 & 6.867 \\
\hline$D_{\mathrm{a}}=18.5, D=10, L=27$ & 5.831 & 0.988 & 6.819 \\
\hline$D_{\mathrm{a}}=18.5, D=12, L=14$ & 5.902 & 0.893 & 6.795 \\
\hline$D_{\mathrm{a}}=18.5, D=12, L=20$ & 5.902 & 0.816 & 6.718 \\
\hline$D_{\mathrm{a}}=18.5, D=12, L=27$ & 5.902 & 0.767 & 6.669 \\
\hline
\end{tabular}

The results from Table 1 show that, The suction capacity under all treatments with throat diameter $D=8 \mathrm{~mm}$ was much better than that under other treatments, and this verified the conclusion that throat diameter $D$ is the most sensitive factor affecting the suction capacity of Venturi injector. The optimal combination of the structural parameters was selected asfollows: 
throat diameter $D=8 \mathrm{~mm}$, slot diameter $D_{\mathrm{a}}=18.5 \mathrm{~mm}$, and throat length $L=14 \mathrm{~mm}$. In this case, the suction capacity of the Venturi injector was $q=1.203 \mathrm{~m}^{3} / \mathrm{h}$.

\section{CONCLUSION}

The following conclusions can be drawn by numerical simulation analysis to the effect of $30 \mathrm{~mm}$ Venturi injector structural parameters on its suction capacity: 1) As keeping other parameters unchanged, the suction capacity of Venturi injector increases with the decrease of throat diameter, or the decrease of throat length, or increase of the slot diameter, or increase of the inlet water pressure. It also decreases with the slot position to the right; 2) The results of Full Factors Experiments show that the most obvious affected factor to the suction capacity is the throat diameter; 3) The optimal structural parameters of Venturi injector with inlet diameter of $30 \mathrm{~mm}$ are $D=8 \mathrm{~mm}, D_{\mathrm{a}}=18.5 \mathrm{~mm}, L=14 \mathrm{~mm}$. In this case, its suction capacity is $q=1$. $203 \mathrm{~m}^{3} / \mathrm{h}$.

\section{REFERENCES}

Bhattarai S P, Huber S, Midmore D J. Aerated subsurface irrigation water gives growth and yield benefits to Zucchini, vegetable soybean and cotton in heavy clay soils. Annals of Applied Biology, 2004,144 (3): 285-298

Bracy R P, Parish R L, Rosendale RM. Fertigation uniformity affected by injector type. Hort Technology, 2003, 13 (1): 103-105

Chen Zuobing, Dou Haijian, Chen Siwei, et al. Numerical research on flow field of Venturi Tube. China Cement, 2005, (4): 61-63 (in Chinese)

Harris G A. Sub-surface drip irrigation - Advantages and Limitations, DPI\&F Note, Brisbane, 2005

He Shaohua, Wen Zhuqing, Lou Tao. Experiment Design and Data Process. Beijing: National Defence Scientech University Press, 2002: 67-69 (in Chinese)

Jiusheng Li, R.E.Yoder, J.Zhang. Simulation of nitrate distribution under drip irrigation using artificial neural networks. Irrigation Science, 2004, 23: 29-37

Johnson A W, Young J R, Thereadgill E D, et al. Chemigation for crop production management. Plant Disease. 1986, 70 (11) : 998-1004

Li Baijun, Mao Hanping, Li Kai. Study on the parallel connected Venturi injectors and their parameters selection. Drainage and Irrigation Machinery. 2001, 19(1): $42-45$ (in Chinese)

Li jiusheng, Zhang jianjun, Xue Kezong. Drip Irrigation Principals for Fertigation and Its Applications. Beijing: Beijing Agricultual Scientech Press, 2003: 10-24 (in Chinese)

Li Yongxin, Li Guangyong, Qiu Xiangyu, et al. Numerical Simulation to the inner flow field of labyrinth type drip with CFD models. 6th National Micro Irrigation Congress. 2004: 275-282 (in Chinese) 
Manzano Juárez J, Palau Salvador G. Hydraulic Modeling of Venturi Injector by Means of CFD. 2005 ASAE Annual International Meeting, paper No. 052070, Tampa Convention Center, Tampa, Florida, U.S.A., 17 - 20 July 2005

Sha Yi, Hou Sujuan. Experimental study on parallel connected Venturi injectors. Irrigation and Drainage Machinery, 1995, (2): 37-39 (in Chinese)

Shen Xuemin, Feng Jun, Zhang Xuejun. Performance research on Venturi injector in sprinkler irrigation system. Water Saving Irrigation, 2001, (1): 20-21 (in Chinese)

Shen Xuemin. Introduction to the 100PS-1 Venturi Injector in Sprinkler Irrigation System. Water Saving Irrigation, 2000, (11): 14-15 (in Chinese)

Wang Fujun. Analyze to CFD(Computational Fluid Dynamics). Beijing: Tsinghua University Press, 2004: 1-259 (in Chinese)

Yuan Z, Choi C Y, Waller P M, Colaizzi P. Effects of liquid temperature and viscosity on Venturi injectors. Transactions of the ASAE, 2000, 43 (6): 1441-1447

Yuan Zhifa, Zhou Jingyu. Experiment Design and Analyze. Beijing: Higher Education Press, 2000: 292-296 (in Chinese)

Zhao Jingcheng, Ren Xiaoli. Sprinkler Engineering Technology. Beijing: China Water Conservation and Hydraulic Electricity Power Publish Press, 1999(in Chinese) 